\title{
ResearchGate
}

See discussions, stats, and author profiles for this publication at:

http://www.researchgate.net/publication/276356763

\section{Hungarian Norms for the Harvard Group Scale of Hypnotic Susceptibility, Form A}

ARTICLE in INTERNATIONAL JOURNAL OF CLINICAL AND EXPERIMENTAL HYPNOSIS · JULY 2015

Impact Factor: 1.38 · DOI: 10.1080/00207144.2015.1031549 · Source: PubMed

CITATIONS

2
DOWNLOADS

5
VIEWS

16

4 AUTHORS, INCLUDING:

\section{Andras Kolto}

Eötvös Loránd University

9 PUBLICATIONS 8 CITATIONS

SEE PROFILE

Katalin Varga

Eötvös Loránd University

41 PUBLICATIONS 100 CITATIONS

SEE PROFILE 
This article was downloaded by: [Kolto Andras]

On: 28 May 2015, At: 03:15

Publisher: Routledge

Informa Ltd Registered in England and Wales Registered Number: 1072954

Registered office: Mortimer House, 37-41 Mortimer Street, London W1T 3J H, UK

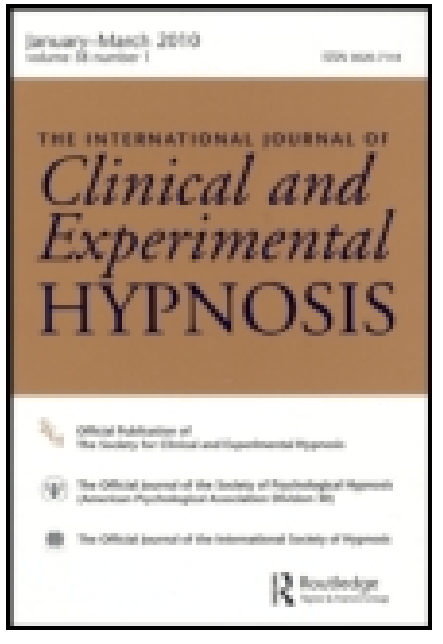

CrossMark

\section{International J ournal of Clinical and Experimental Hypnosis}

Publication details, including instructions for authors and subscription information:

http:/ / www.tandfonline.com/loi/ nhyp20

\section{Hungarian Norms for the Harvard Group Scale of Hypnotic Susceptibility, Form A}

András Költőa ${ }^{a}$, Anna C. Gősi-Greguss ${ }^{a}$, Katalin Varga ${ }^{a}$ \& Éva I. Bányai ${ }^{a}$

a Eötvös Loránd University, Budapest, Hungary

Published online: 15 May 2015.

Click for updates

To cite this article: András Költő, Anna C. Gősi-Greguss, Katalin Varga \& Éva I. Bányai (2015) Hungarian Norms for the Harvard Group Scale of Hypnotic Susceptibility, Form A, International J ournal of Clinical and Experimental Hypnosis, 63:3, 309-334, DOI: $10.1080 / 00207144.2015 .1031549$

To link to this article: http:// dx. doi.org/ 10.1080/00207144.2015.1031549

\section{PLEASE SCROLL DOWN FOR ARTICLE}

Taylor \& Francis makes every effort to ensure the accuracy of all the information (the "Content") contained in the publications on our platform. However, Taylor \& Francis, our agents, and our licensors make no representations or warranties whatsoever as to the accuracy, completeness, or suitability for any purpose of the Content. Any opinions and views expressed in this publication are the opinions and views of the authors, and are not the views of or endorsed by Taylor \& Francis. The accuracy of the Content should not be relied upon and should be independently verified with primary sources of information. Taylor and Francis shall not be liable for any losses, actions, claims, proceedings, demands, costs, expenses, damages, and other liabilities whatsoever or howsoever caused arising directly or indirectly in connection with, in relation to or arising out of the use of the Content. 
This article may be used for research, teaching, and private study purposes.

Any substantial or systematic reproduction, redistribution, reselling, loan, sublicensing, systematic supply, or distribution in any form to anyone is expressly forbidden. Terms \& Conditions of access and use can be found at http:// www.tandfonline.com/page/terms-and-conditions 


\title{
HUNGARIAN NORMS FOR THE HARVARD GROUP SCALE OF HYPNOTIC SUSCEPTIBILITY, FORM A
}

\author{
András Költő, Anna C. Gősi-Greguss, Katalin Varga, \\ AND ÉvA I. BÁNYAI
}

Eötvös Loránd University, Budapest, Hungary

\begin{abstract}
Hungarian norms for the Harvard Group Scale of Hypnotic Susceptibility, Form A (HGSHS:A) are presented. The Hungarian translation of the HGSHS:A was administered under standard conditions to 434 participants (190 males, 244 females) of several professions. In addition to the traditional self-scoring, hypnotic behavior was also recorded by trained observers. Female participants proved to be more hypnotizable than males and so were psychology students and professionals as compared to nonpsychologists. Hypnotizability varied across different group sizes. The normative data-including means, standard deviations, and indicators of reliability-are comparable with previously published results. The authors conclude that measuring observer-scores increases the ecological validity of the scale. The Hungarian version of the HGSHS:A seems to be a reliable and valid measure of hypnotizability.
\end{abstract}

The mystery of hypnosis cannot be fully solved without understanding why people are so different in how they respond to hypnosis. It is a general experience of hypnotists - even if they do not use standard methods to check their subjects' hypnotic responsiveness-that some subjects are very easy to hypnotize, whereas others seem to respond to suggestions to a relatively lesser degree. Hilgard (1965) conceptualized hypnotizability as the degree of hypnotic depth someone could experience under standardized circumstances.

Since the late 1950s, standard scales have been created to measure hypnotizability in a reliable and reproducible way. One of the most important of these scales is the Harvard Group Scale of Hypnotic Susceptibility, Form A (HGSHS:A), developed by Shor and Orne (1962). It is a group adaptation of the individually administered Stanford

Manuscript submitted October 16, 2013; final revision accepted January 22, 2014.

Address correspondence to András Költő, Doctoral School of Psychology and Department of Affective Psychology, Institute of Psychology, Eötvös Loránd University, Izabella utca 46. Pf. 755, Budapest, H-1384, Hungary. E-mail: kolto.andras@gmail.com 
Hypnotic Susceptibility Scale, Form A (SHSS:A; Weitzenhoffer \& Hilgard, 1959; its slightly modified version for retesting is the B form, abbreviated SHSS:B). The HGSHS:A primarily serves for prescreening the hypnotizability of large groups to select subjects of different levels of hypnotic responsiveness for successive experiments. It is worthy of note, however, that attempts to measure hypnotic depth can be traced to A.-A. Liébeault in 1889, although the first standardized scale was developed by Friedlander and Sarbin in 1938.

Barnier and McConkey (2004) examined the frequency of using hypnotizability scales as reported in empirical articles in the International Journal of Clinical and Experimental Hypnosis between 1992 and 2003. They found that by far the most used scale was the HGSHS:A-it was applied in 76 studies or $46.3 \%$ of all articles that reported the use of a standard method to test hypnotic responsiveness. It was followed by the Stanford Hypnotic Susceptibility Scale, Form C (SHSS:C, Weitzenhoffer \& Hilgard, 1962), the "gold standard" of measures for hypnotizability. Without doubt, the largest corpus of hypnosis research consists of investigations where the HGSHS:A was the first or only measure of hypnotizability. Nowadays, even researchers in areas "neighboring" hypnosis (e.g., cognitive neuroscience) recognize the importance of controlling subjects for hypnotizability, and they use the HGSHS:A as a prescreening device (Oakley, 2006). This is a so-called "extrinsic" use of hypnosis (Reyher, 1962).

The importance of the HGSHS:A is also indicated by fact that it already has normative data in 14 countries. Original norms were set in the United States (Shor \& Orne, 1963), followed by normative data of the Hungarian (published hitherto only in Hungarian, by Greguss, Bányai, Mészáros, Csókay, \& Gerber, 1975), Australian (Sheehan \& McConkey, 1979), Canadian (Montréal; Laurence \& Perry, 1982), German (Bongartz, 1985), Spanish (Lamas, del Valle-Inclan, Blanco, \& Diaz, 1989), Danish (Zachariae, Sommerlund, \& Molay, 1996), Finnish (Kallio \& Ihamuotila, 1999), Italian (De Pascalis, Russo, \& Marucci, 2000), Romanian (David, Montgomery, \& Holdevici, 2003), Swedish (Bergman, Trenter, \& Kallio, 2003), Israeli (Lichtenberg, 2008), Polish (Siuta, 2010), and Portuguese (Carvalho, 2013) versions. In spite of the apparent cultural differences, normative data are quite similar in their psychometric properties. In this article, we present recently obtained data using the Hungarian translation of the HGSHS:A, and we compare these data with the previously published reference samples.

An inconsistent gender-specific pattern was observed in the normative samples. Although no gender differences were found in the United States, original Hungarian, Australian, Canadian, German, Spanish, Finnish, Romanian, Israeli, and Portuguese investigations, women proved to be significantly more hypnotizable than men in the Danish, 
Italian, Swedish, and Polish norms. At a first glance, no definite time trend or cultural pattern can be seen in these gender differences across the countries. However, Rudski, Marra, and Graham (2004), analyzing data of a large U.S. sample, also found that females score significantly higher on the HGSHS:A than males.

Originally, the HGSHS:A scores were based on the subjects' report of their behavior, measured by a booklet containing the 12 test suggestions of the scale: The subject has to indicate whether or not he or she accomplished respective suggestion by the given criteria. A vast majority of research papers, including those on the normative data of the HGSHS:A, report the use of this kind of scoring ("self-scores"). There is, however, another method to estimate the subjects' hypnotic capacity. That is observation of the subjects by another person who is trained to detect and decide if the subject performed the given test suggestion or not. It results in the so-called "observer-scores" (Bentler \& Hilgard, 1963). Novel to the previous normative investigations, in Hungary, the HGSHS:A sessions included not only the subjects' observation-which allowed us to report not just the self-scores-but the observer-scores, too. Although self-scores and observer-scores show a strong correlation (usually around $r=.80$ ), Varga, Farkas, and Mérö (2012) pointed out that the composition of the two scores shows great differences. The measure of interrater reliability between observer-scores and subjective scores, Cohen's kappa yielded a value of .563 , indicating only a moderate agreement between subject and one's observer. Still, even if observer-scoring and self-scoring are discrepant to some extent, they increase the convergent validity of the results and serve as complementary measures of hypnotizability.

The majority of hypnotherapeutic interventions are done "face-toface," with just the therapist and the patient present. Maybe that is the reason why individual hypnosis sessions also prevail in experimental settings, and group hypnosis just serves as a prescreening method. The characteristics of group hypnosis-and the similarities and differences between group and individual administrations-seem to be a rather neglected area in hypnosis research. HGSHS:A is not just a means of identifying low, medium, and high hypnotizable subjects, but it is also a strongly standardized group situation. Therefore, it would be a feasible tool for investigating various social group processes and phenomena of group dynamics. HGSHS:A is functionally equivalent to SHSS:A, since they only differ in the context of administration (group versus individual testing): Comparing them to each other may shed light on the differences between group and individual hypnosis. Such a comparison may also have important implications for group hypnotherapy. Despite Araoz's call for more research on group therapy (1979), this aspect of hypnosis is still not well scrutinized. Still, group 
hypnotherapy seems to be slightly more effective in smoking cessation than individual intervention (Riegel, 2013); it seems to be similarly effective in the treatment of irritable bowel syndrome (Harvey, Gunary, Hinton, \& Barry, 1989). As many national healthcare systems press practitioners for cost-effective methods, a better understanding of how and when group therapy can replace or supplement individual treatment might also help meet such demands.

When comparing hypnotizability tested in individual and group settings, Bentler and Hilgard (1963) did not find remarkable differences in the hypnotizability scores. Bentler and Roberts, contrasting HGSHS:A administration for 4 to 6 subjects against group sessions including 39 to 52 subjects, found no difference in the scores, either. Based on these observations, HGSHS:A sessions have been regularly administered to an uncountable number of subjects around the world; headcounts in these groups vary from 4 to 6 to even 50 to 250 (Sadler \& Woody, 2004). Still, researchers may be a bit too quick in stating that such diversity in group size does not make any difference in the participants' hypnotizability. Even if an HGSHS:A session for 6 subjects follows exactly the same procedure as a session with 200, the atmosphere may be different and may evoke opposite social processes. In our opinion, further investigation is needed to probe whether HGSHS:A scores administered to different size groups are comparable.

Normative data on national HGSHS:A scores were already published in Hungarian, based on an investigation carried out with 133 subjects (Greguss, 1976; Greguss et al., 1975). Their HGSHS:A observer-scores $(M=5.57, S D=2.68)$ and self-scores $(M=5.59, S D=3.02)$ did not differ significantly, $t(132)=0.14, n s$, and had a correlation of $r=.80$, $p<.001$. No significant gender differences were found. Their results strongly support that the Hungarian version of the HGSHS:A was in accordance with other adaptations until then and proved to be suitable for testing hypnotic ability.

Almost 40 years have passed since the HGSHS:A was adapted to Hungarian. Benham, Smith, and Nash (2002) detected in their betweenlab examination that standard hypnotizability scores exhibit a statistically significant and continuous increase since the 1960s. Our analysis, carried out on aggregated HGSHS:A, SHSS:A, and SHSS:B data collected in our laboratory from 1973 to 2010, supported the notion that hypnotizability scores are increasing over time (Költő, Gősi-Greguss, Varga, \& Bányai, 2014). This is one of the reasons why we report the normative data of the HGSHS:A from a more recent sample rather than all of the data collected in the last 4 decades. The other reason is that the majority of the normative studies were apparently based on rather synchronic (cross-sectional) and not diachronic (longitudinal) 
examination. ${ }^{1}$ Therefore, we decided to publish the Hungarian norms in the same fashion.

\section{METHOD}

\section{Recruitment and Sampling Process}

Some of the sessions where the HGSHS:A was administered served as an initiation to hypnosis-providing an experience of altered states of consciousness - to undergraduate psychology students in lectures or in seminars on hypnosis-related topics held by the authors. Another part of the sessions served as a prescreening for hypnotizability of the subjects in the context of various psychological experiments, including studying affective, cognitive, and psychophysiological mechanisms, genetic determinants, phenomenological experiences, altered states of consciousness, archaic involvement, interactional synchrony, and other hypnosis-related topics. In these experiments, various groups of participants were tested, including undergraduate students of psychology, arts, economy, law, and technology, and adults of diverse professions.

This large variety also means that various recruitment methods were applied. Some subjects obtained information about the experiments from flyers and posters that we placed in social spaces of the universities. Others were invited via online forums. Subjects were asked to tell their friends who might be interested and were eligible to participate (healthy adults over 18 who had never been hypnotized before) about the experiments.

Although the psychology students had the opportunity to participate in these hypnosis sessions within the frame of seminars or lectures they attended, participation was never obligatory. All other subjects were also volunteers. None of the subjects were paid or rewarded with academic credits or any other form of remuneration for participating.

\section{Subjects}

Four hundred and thirty-four subjects were hypnotized using the HGSHS:A between 2009 and 2013. To the best of our knowledge, none of them had experienced hypnosis before. One hundred and ninety males (44\%) and 244 females (56\%) participated. Due to the recruitment methods-somewhat contrary to most of the previously published normative studies-the sample consisted of subjects with

\footnotetext{
${ }^{1}$ Among the original normative studies, the only apparent exception seems to be Sheehan and McConkey's (1979) paper, in which they report on data collected for 3 years. For the later Australian normative examination of HGSHS:A (McConkey, Barnier, Maccallum, \& Bishop, 1996), data were collected for 8 years, but the authors-although reporting the data in a yearly breakdown-do not analyze the temporal aspects.
} 
various ages and professions. The average age was 26.3 years $(S D=$ 8.05). The youngest subject was 18 , while the oldest was 59 years old. Three hundred and forty-five participants provided information about their profession. Most of them (31\%) were psychology students or psychologists, while others were students or professionals in areas of office work, economy/banking/entrepreneurship, healthcare (nonpsychological), information technology (IT)/engineering, law, commerce/services/catering, arts/culture/media, management/human resources (HR), and education/science. Some subjects were unemployed or had already retired. For a meaningful comparison, the professions were categorized as follows: psychology/healthcare $(n=$ $112,32.5 \%)$, culture/science $(n=58,16.8 \%)$, IT/engineering $(n=56$, $16.2 \%)$, other $(n=51,14.8 \%)$, economy/commerce $(n=39,11.3 \%)$, and legal/administrative $(n=29,8.4 \%)$.

The sample was also heterogeneous according to the subjects' permanent residence. Of the 311 subjects who provided information on their residence, 191 (61.4\%) came from Budapest and its surroundings, $45(14.5 \%)$ were from county capitals, and $75(24.1 \%)$ came from other settlements.

\section{Instrument and Procedure}

The Harvard Group Scale of Hypnotic Susceptibility was translated to Hungarian in early 1975 by the second (A. C. G-G.) and the last (É. I. B.) authors and their colleagues: István Mészáros, László Csókay, and Annamária Gerber. Since 1975, the HGSHS:A has been regularly used in our department, in other hypnosis laboratories in Hungary, and-occasionally_in clinical practice. In our laboratory, it has been administered to more than 2,500 subjects.

Hypnosis induction and original test suggestions were given to the subjects in a standard way. The Hungarian version of the HGSHS:A was administered orally by the authors and other licensed hypnosis experts, accordingly to the standard instructions, in a total of 31 sessions. Three female and three male ${ }^{2}$ psychologists conducted the hypnosis sessions, with 4 to 45 years of experience in the academic and clinical fields of hypnosis. The sessions took place in seminar rooms and lecture halls of the university. In sum, 29 group sessions were conducted. The headcount of the participants varied from 6 to 49 subjects per session; the average headcount was 14 .

At every HGSHS:A administration, there was another licensed hypnotherapist present in addition to the hypnotist in order to attend

\footnotetext{
${ }^{2}$ Our findings on how the hypnotists' gender (previously investigated by Coe, 1976, and D'Eon, Mah, Pawlak, \& Spanos, 1979) influences hypnotizability will be presented in a forthcoming article.
} 
to rarely occurring but possible unexpected reactions (e.g., dizziness, headache, etc.). Trained observers recorded how the subjects responded to the suggestions. The observers were undergraduate and graduate psychology students who took part in methodological seminars on hypnosis research and volunteered to participate in some of our research projects. They recorded the observable behavior of the subjects and decided-based on the standard criteria-whether the subject carried out the suggestion or not. One observer registered the behavior of 2 to 5 subjects. Following dehypnosis, subjects evaluated their own reactions to the suggestions in a response booklet according to the standard protocol. Since the amnesia item is scored on the basis of the number of test suggestions mentioned by the subject in the response booklet before the suggestion is lifted, self- and observer-scores of this item are necessarily identical. After the subjects completed the response booklets, they handed them back to the observers who evaluated the amnesia item. Thus, every subject had two scores varying from 0 to 12 , based on self-evaluation (self-score) and the observers' record (observer-score). Feedback was then given to the participants about both their selfscores and the observer-scores by the hypnotist. A brief discussion was initiated to enable the subjects to share their experiences.

\section{Ethical Considerations}

All subjects signed a written consent form before hypnosis took place. The hypnosis sessions were conducted complying with the Professional Ethical Code of the Hungarian Psychological Association. If the context of the given session required, permission from the Ethical Committee of the university or higher authorities was obtained.

\section{Data Analysis}

Descriptive data and distributions were calculated. Gender differences were analyzed and the present sample was contrasted to samples of other HGSHS:A research projects using two-tailed Student $t$ tests (if the variances were not homogenous, Mann-Whitney $U$ tests were used instead). ${ }^{3}$ Differences in hypnotizability scores by profession and residence of the subjects and those across different-sized groups were examined with one-way analysis of variance (ANOVA).

\footnotetext{
${ }^{3}$ When comparing Hungarian hypnotizability scores to reference samples, due to the lack of the raw data we had to use online calculators. For comparing samples, a Usable Stats 2-Sample $t$ test Calculator was used (http://www.usablestats.com/calcs/ 2samplet\&summary=1). Effect sizes were computed by Dr. Lee A. Becker's instrument (http://www.uccs.edu/lbecker/index.html\#means and standard deviations). As it was not possible to check variance homogeneity, the results of parametric tests will be reported in all cases, noting that nonparametric comparisons-automatically computed by the $t$ test calculator-yielded an identical pattern.
} 
Reliability analysis (measuring point-biserial item-scale correlations, and Kuder-Richardson's KR-20 reliability coefficients) was performed. To compare Hungarian data with reference samples, item-total correlations of each test suggestion were ranked and Spearman's rank-order correlations between them were computed. Analyses were carried out with SPSS 19.0 statistical program for Windows. The significance level was set at .05, two-tailed. For significant results, effect sizes were also calculated. Due to a large number of comparisons, significance levels of the respective tests were adjusted using the Holm-Bonferroni procedure (Holm, 1979).

\section{REsUlts}

\section{Mean Total Scores and Distributions}

Item pass rates, mean scores, and standard deviations of the Hungarian and previously published versions of the HGSHS:A are presented in Table 1. Self-scores and observer-scores are displayed separately. Results on the two scoring systems yielded a high correlation $(r=.819, p<.001)$.

Beside the comparisons with reference samples, our results were contrasted to findings from four other studies. We checked our data against the original Hungarian normative sample (Greguss, 1976), including self-scores and observer-scores of 133 subjects. As the HGSHS:A has been continuously used in our laboratory since 1975, we were able to contrast the normative data presented here to the sample aggregated over time, containing self-scores of 1,898 subjects and observer-scores of 1,713 subjects. ${ }^{4}$ As David et al. (2003) noted, more recent (and larger) U.S. samples of the HGSHS:A than the original reference sample already exist. They suggested checking normative data against them. That was the reason why we also contrasted our data to a newer study, namely, the findings of Rudski et al. (2004), including data on selfscores of 1,872 subjects. Another large-scale HGSHS:A research $(N=$ 4,752) was conducted in Australia by McConkey, Barnier, Maccallum, and Bishop (1996). Item pass rates, mean scores, and standard deviations of these studies—as compared to the present sample — can be seen in Table 2.

The distribution of Hungarian self-scores and observer-scores are presented in Table 3. Subjects were classified by their level of

\footnotetext{
${ }^{4}$ In some sessions of hypnotizability testing, no observers were present. That is the reason why the sample contains different numbers of self-scores and observer-scores. For further properties of the sample aggregated from 1975 to 2010-including the effect of time and gender-see Költő, Gősi-Greguss, Varga, and Bányai (2014).
} 


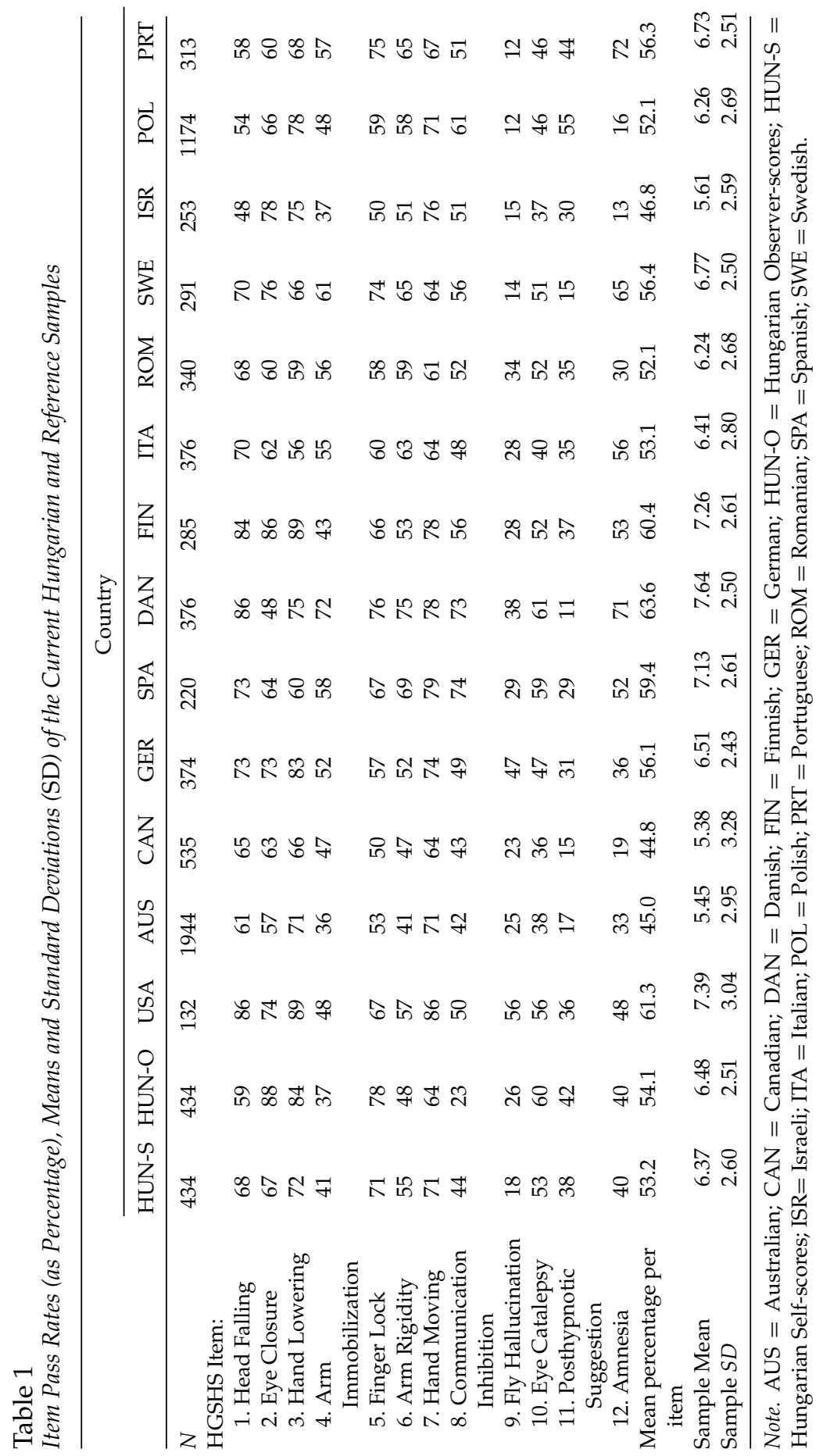




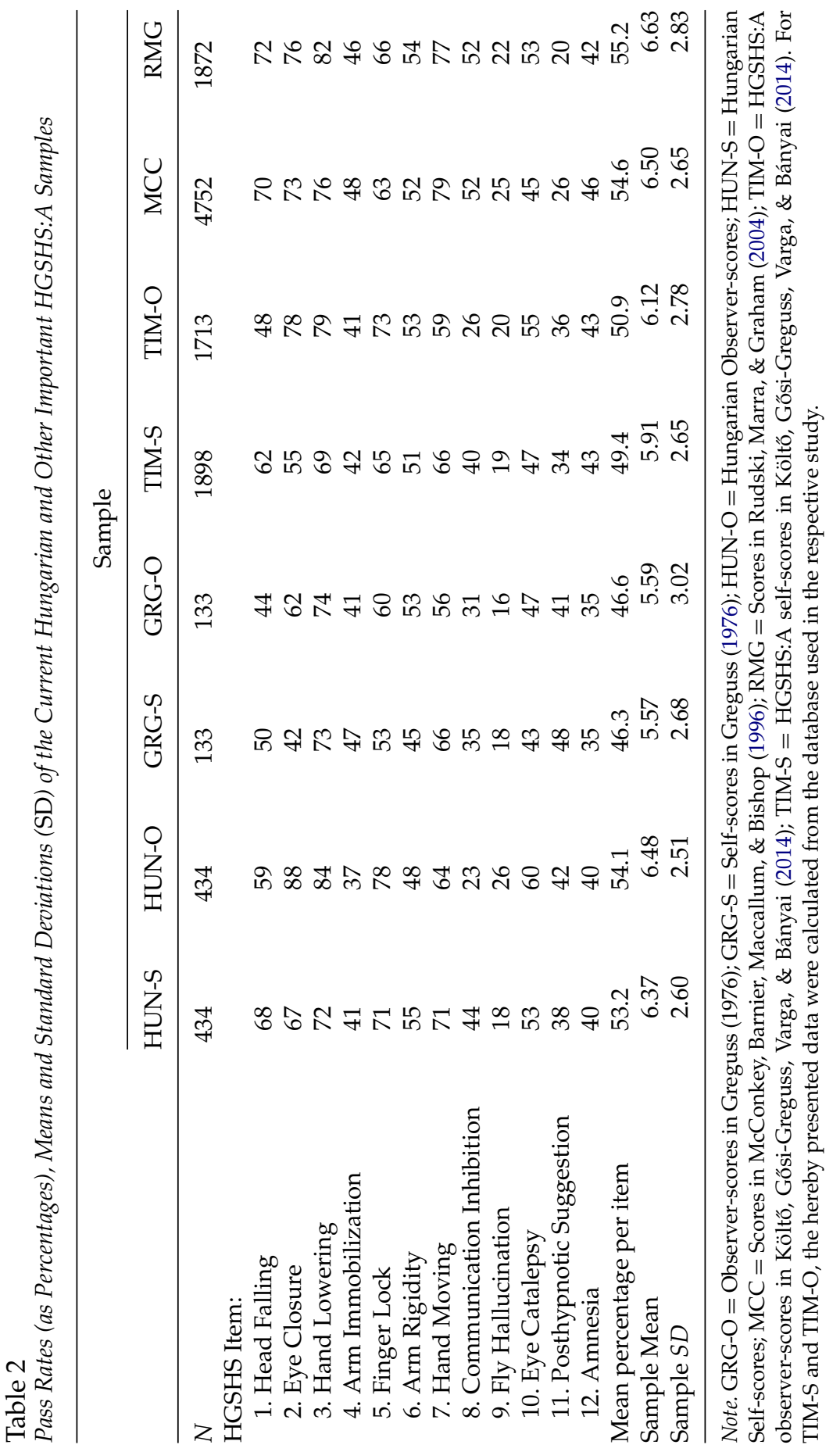


Table 3

HGSHS:A Self-Score and Observer-Score Distributions in the Hungarian Sample $(\mathrm{N}=434)$

\begin{tabular}{|c|c|c|c|c|c|c|}
\hline \multirow[b]{2}{*}{ Score } & \multicolumn{3}{|c|}{ HGSHS Self-Scores } & \multicolumn{3}{|c|}{ HGSHS Observer-Scores } \\
\hline & $n$ & $\begin{array}{l}\% \text { of } \\
\text { cases }\end{array}$ & $\begin{array}{c}\text { Cumulative } \\
\%\end{array}$ & $n$ & $\begin{array}{l}\% \text { of } \\
\text { cases }\end{array}$ & $\begin{array}{c}\text { Cumulative } \\
\%\end{array}$ \\
\hline 0 & 1 & 0.2 & 0.2 & 2 & 0.5 & 0.5 \\
\hline 1 & 14 & 3.2 & 3.5 & 10 & 2.3 & 2.8 \\
\hline 2 & 19 & 4.4 & 7.8 & 15 & 3.5 & 6.2 \\
\hline 3 & 41 & 9.4 & 17.3 & 36 & 8.3 & 14.5 \\
\hline 4 & 40 & 9.2 & 26.5 & 34 & 7.8 & 22.4 \\
\hline 5 & 45 & 10.4 & 36.9 & 46 & 10.6 & 32.9 \\
\hline 6 & 47 & 10.8 & 47.7 & 64 & 14.7 & 47.7 \\
\hline 7 & 57 & 13.1 & 60.8 & 71 & 16.4 & 64.1 \\
\hline 8 & 72 & 16.6 & 77.4 & 62 & 14.3 & 78.3 \\
\hline 9 & 51 & 11.8 & 89.2 & 45 & 10.4 & 88.7 \\
\hline 10 & 32 & 7.4 & 96.5 & 30 & 6.9 & 95.6 \\
\hline 11 & 12 & 2.8 & 99.3 & 12 & 2.8 & 98.4 \\
\hline 12 & 3 & 0.7 & 100.0 & 7 & 1.6 & 100.0 \\
\hline High (10-12) & 115 & 26.5 & 26.5 & 97 & 22.4 & 22.4 \\
\hline Medium (5-9) & 272 & 62.7 & 89.2 & 288 & 66.4 & 88.7 \\
\hline Low $(0-4)$ & 47 & 10.8 & 100.0 & 49 & 11.3 & 100.0 \\
\hline
\end{tabular}

hypnotizability using Kirsch, Council, and Wickless's (1990) criteria. Subjects were categorized as high (scoring 10 to 12), medium (scoring 5 to 9 ), and low (scoring 0 to 4 ) hypnotizable. Using self-scoring and observer-scoring, similar proportions of subjects fell into each category (11\% low, 63-66\% medium, and 22-27\% high).

To check if the Hungarian scores differ from the reference samples, a series of two-tailed independent-sample $t$ tests were performed (see the upper part of Table 3). No significant differences emerged between Hungarian observer-scores $(M=6.48, S D=2.51)$ and Hungarian selfscores $(M=6.37, S D=2.60)$ either when contrasted to each other or when they were contrasted to Romanian, Polish, Italian, German, Portuguese, or Swedish data. Hungarian self-scores were significantly lower than the Spanish and U.S. scores, but observer-scores were not. Hungarian hypnotizability scores (irrespective of self-scoring or observer-scoring) were significantly higher than Canadian, Australian, and Israeli data but significantly lower than Finnish and Danish references. Effect sizes - as measured with Cohen's $d$ or effect size $r$-were, however, rather small. Effect size $r$ values did not exceed .30, which would have indicated medium effect size (Cohen, 1988).

Beside the comparisons with reference samples, our results were contrasted to findings from the abovementioned four other studies 
(see lower part of Table 4). We checked our data against the original Hungarian normative sample (Greguss, 1976). Contrasting both selfscores and observer-scores, those who were tested between 2009 and 2012 exhibited significantly higher hypnotizability then those who were examined in 1975, but the magnitude of the effect was small. The present data were compared to the sample aggregated in our laboratory between 1975 and 2010, too. Hypnotizability in the present normative sample was higher than that of the aggregate sample, though not all comparisons of self-scores and observer-scores yielded a significant difference. Effect sizes suggest that the differences, even if significant, were negligible. As David et al. (2003) noted, more recent (and larger) U.S. samples of the HGSHS:A than the original reference sample already exist. They suggested checking normative data against them. That was why we also contrasted our data to a newer study, namely, to the findings of Rudski et al. (2004). No significant difference emerged between their results and the Hungarian data presented here. Hypnotizability of the sample studied by McConkey et al. (1996) was not significantly different from ours, either.

\section{Differences in Hypnotic Susceptibility by Age, Gender, Profession, and Residence}

Age showed a significant negative, although not too large, correlation with HGSHS:A observer-score $(r=-.168, p<.001)$ but not with self-score $(r=-.080, p<.1)$. Effects of other background factors on the HGSHS:A scores are displayed in Table 5. According to self-scores, female subjects proved to be more hypnotizable than males. The same gender difference was found in observer-scores. The effects have a small magnitude. When grouping subjects into professionals/students of psychology versus all other areas, the psychology group had a significantly higher observer-score than the nonpsychologists (with a small effect size). In self-scoring, however, no significant difference emerged. When using more detailed categories, people of different professions/areas did not exhibit significant differences in their hypnotizability, as tested by ANOVA. Still, it is important to note that psychology students/professionals had the highest hypnotizability scores. This result is in line with our previous finding that hypnotists, measured by SHSS:B, tend to be more hypnotizable than the general population (Gôsi-Greguss, Bányai, \& Varga, 1996). Place of residence did not discriminate between subjects' hypnotic responsiveness, either.

\section{Differences in Hypnotizability as a Function of Group Size}

In sum, 29 group sessions were conducted with different headcounts. Nine of the HGSHS:A sessions included 6 to 10 subjects ("small" 
Table 4

Comparison of Hungarian HGSHS:A Scores With Scores in Reference and Other Samples

\begin{tabular}{|c|c|c|c|c|c|}
\hline Contrast & $t$ & $d f$ & $p^{\mathrm{a}}$ & $d$ & $r_{E S}^{\mathrm{b}}$ \\
\hline \multicolumn{6}{|c|}{ Hungarian Self-Scores Contrasted to Reference Samples } \\
\hline HUN-S vs. CAN & 5.117 & 967 & $<.0001$ & 0.329 & .162 \\
\hline HUN-S vs. AUS & 5.998 & 2376 & $<.0001$ & 0.246 & .122 \\
\hline HUN-S vs. ISR & 3.707 & 685 & .0002 & 0.283 & .14 \\
\hline HUN-S vs. ROM & 0.681 & 772 & ns & & \\
\hline HUN-S vs. POL & 0.773 & 1606 & $n s$ & & \\
\hline HUN-S vs. ITA & -0.211 & 808 & ns & & \\
\hline HUN-S vs. HUN-O & 0.634 & 866 & ns & & \\
\hline HUN-S vs. GER & -0.786 & 806 & ns & & \\
\hline HUN-S vs. PRT & -1.894 & 745 & $n s$ & & \\
\hline HUN-S vs. SWE & -2.062 & 723 & $n s$ & & \\
\hline HUN-S vs. SPA & -4.131 & 652 & $<.0001$ & -0.324 & .159 \\
\hline HUN-S vs. FIN & -4.483 & 717 & $<.0001$ & -0.335 & .165 \\
\hline HUN-S vs. USA & -3.789 & 564 & $<.0002$ & 0.283 & .14 \\
\hline HUN-S vs. DAN & -7.058 & 808 & $<.0001$ & -0.469 & .241 \\
\hline
\end{tabular}

Hungarian Observer-Scores Contrasted to Reference Samples

\begin{tabular}{lrrccc} 
HUN-O vs. ITA & -0.105 & 808 & $n s$ & & \\
HUN-O vs. POL & 0.914 & 1606 & $n s$ & & \\
HUN-O vs. ROM & 1.281 & 772 & $n s$ & & \\
HUN-O vs. ISR & 4.331 & 685 & $<.0001$ & 0.331 & .163 \\
HUN-O vs. AUS & 6.749 & 2376 & $<.0001$ & 0.277 & .137 \\
HUN-O vs. CAN & 5.752 & 967 & $<.0001$ & 0.369 & .181 \\
HUN-O vs. GER & -0.172 & 806 & $n s$ & & \\
HUN-O vs. PRT & -1.343 & 745 & $n s$ & & \\
HUN-O vs. SWE & -1.527 & 723 & $n s$ & & \\
HUN-O vs. SPA & -3.087 & 652 & $n s$ & -0.242 & .12 \\
HUN-O vs. FIN & -4.012 & 717 & $<.0001$ & -0.299 & .148 \\
HUN-O vs. USA & -3.464 & 564 & $n s$ & -0.292 & .144 \\
HUN-O vs. DAN & -6.572 & 808 & $<.0001$ & -0.462 & .225 \\
& Contrasted to Other Samples & & \\
HUN-S vs. GRG-S & 2.911 & 565 & .0038 & 0.245 & .122 \\
HUN-S vs. GRG-O & 3.082 & 565 & .0022 & 0.259 & .128 \\
HUN-O vs. GRG-O & 3.404 & 565 & .0008 & 0.286 & .142 \\
HUN-O vs. GRG-S & 3.599 & 565 & .0004 & 0.302 & .149 \\
HUN-S vs. TIM-S & 3.274 & 2330 & .001 & 0.136 & .068 \\
HUN-S vs. TIM-O & 1.695 & 2145 & $n s$ & & \\
HUN-O vs. TIM-S & 4.082 & 2330 & $<.0001$ & 0.169 & .084 \\
HUN-O vs. TIM-O & 2.455 & 2145 & $n s$ & & \\
HUN-S vs. MCC & -0.98 & 5184 & $n s$ & & \\
\hline
\end{tabular}


Table 4

(Continued)

\begin{tabular}{llclll}
\hline Contrast & $t$ & $d f$ & $p^{\mathrm{a}}$ & $d$ & $r_{E S}^{\mathrm{b}}$ \\
\hline HUN-O vs. MCC & -0.151 & 5184 & $n s$ & \\
HUN-S vs. RMG & -1.75 & 2304 & $n s$ & \\
HUN-O vs. RMG & -1.015 & 2304 & $n s$ & \\
\hline
\end{tabular}

Note. AUS = Australian; CAN = Canadian; DAN = Danish; FIN = Finnish; GER = German; GRG-O = Observer-scores in Greguss (1976); GRG-S = Self-scores in Greguss (1976); HUN-O = Hungarian observer-scores; HUN-S = Hungarian self-scores; ISR= Israeli; ITA = Italian; MCC = Scores in McConkey, Barnier, Maccallum, \& Bishop (1996); $\mathrm{POL}=$ Polish; PRT = Portuguese; RMG = Scores in Rudski, Marra, \& Graham (2004); $\mathrm{ROM}=$ Romanian; $\mathrm{SPA}=$ Spanish; $\mathrm{SWE}=$ Swedish; TIM-O = HGSHS:A observer-scores in Költő, Gősi-Greguss, Varga, \& Bányai (2014); TIM-S = HGSHS:A self-scores in Költő, Gősi-Greguss, Varga, \& Bányai (2014).

${ }^{a}$ Adjusted for Holm-Bonferroni criteria. ${ }^{b}$ Effect size $r$.

groups). Sixteen groups comprised 11 to 20 subjects ("medium-sized" groups). At four sessions, 21 to 49 subjects were present ("large" groups). HGSHS:A self- and observer-score means and standard deviations are displayed in Table 6.

ANOVA revealed that HGSHS:A scores are significantly different across various group sizes. For observer-scores, $F(2,431)=4.629, p=$ .01 , although $\omega=.126$, indicating that the effect is small. For self-scores, $F(2,431)=3.295, p=.038 ; \omega=.102$, showing small effect size. For post hoc contrasting, Hochberg's GT2 procedure was used, ${ }^{5}$ yielding significant differences between small versus medium and small versus large groups; hypnotizability of subjects in medium versus large groups did not differ significantly. The same pattern was found in self- and observer-scores. Although the magnitude of the effect is rather small, the hypnotizability of subjects tested in small groups seems to be significantly lower than that of those who were tested in larger $(n=11$ to 49) groups. It has to be noted, however, that the possible interaction between group size and the hypnotist (the "between hypnotist effect") was not controlled (i.e., if group size had a differential effect on the hypnotizability of subjects with different hypnotists).

\section{Item Difficulty}

For item pass rates of the test suggestions of the Hungarian and the reference samples, return to Tables 1 and 2. The highest item pass rates obtained in the Hungarian sample, based on self-evaluation, were hand lowering $(72 \%)$, hands moving $(71 \%)$, and eye closure $(67 \%)$.

\footnotetext{
${ }^{5}$ Detailed information and data on post hoc comparisons are available from the corresponding author.
} 


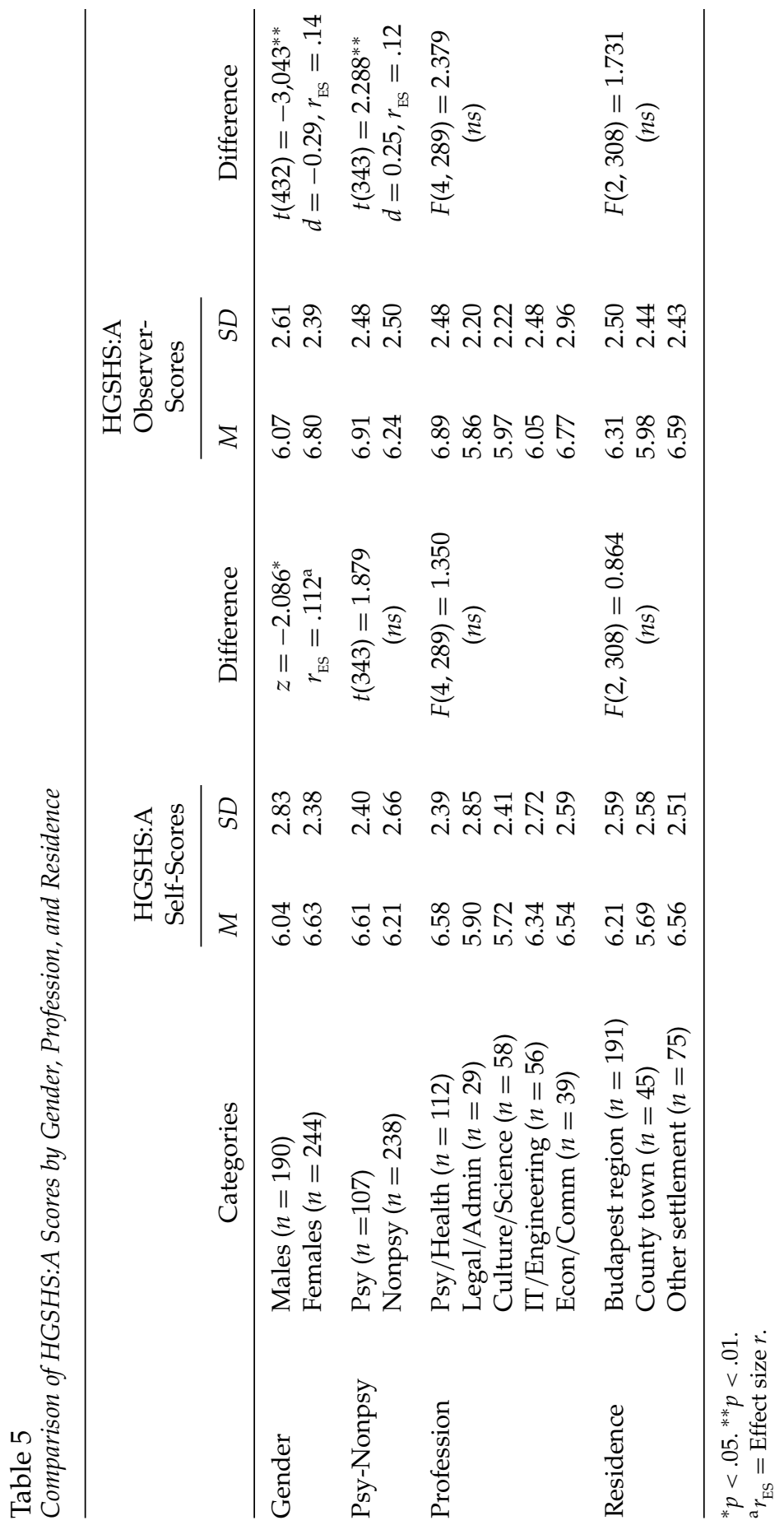


Table 6

Hypnotizability in Small, Medium, and Large Groups

\begin{tabular}{|c|c|c|c|c|c|}
\hline \multirow[b]{2}{*}{ Group Size } & \multirow[b]{2}{*}{$N$} & \multicolumn{2}{|c|}{$\begin{array}{l}\text { HGSHS:A } \\
\text { Self-Scores }\end{array}$} & \multicolumn{2}{|c|}{$\begin{array}{c}\text { HGSHS:A } \\
\text { Observer-Scores }\end{array}$} \\
\hline & & $M$ & $S D$ & $M$ & $S D$ \\
\hline $\begin{array}{l}\text { Small } \\
\text { (6 to } \\
10 \text { subjects) }\end{array}$ & 81 & 5.70 & 2.60 & 5.74 & 2.35 \\
\hline $\begin{array}{l}\text { Medium } \\
\text { (11 to } \\
20 \text { subjects) }\end{array}$ & 214 & 6.53 & 2.62 & 6.57 & 2.47 \\
\hline $\begin{array}{l}\text { Large } \\
\text { ( } 21 \text { to } \\
49 \text { subjects) }\end{array}$ & 139 & 6.50 & 2.53 & 6.76 & 2.58 \\
\hline
\end{tabular}

Observers recorded the highest item pass rates on suggestions for eye closure $(88 \%)$, hand lowering $(84 \%)$, and finger lock (78\%). Lowest rates, according to subjects self-scoring, were fly hallucination $(18 \%)$, posthypnotic suggestion (38\%), and posthypnotic amnesia (40\%), while the lowest item pass rates according to the observer-scoring were communication inhibition (23\%), fly hallucination $(26 \%)$, and arm immobilization (37\%).

Until now, the smallest proportion of subjects passing the suggestion for communication inhibition has been reported in Australia (42\%); we found that, according to the observers, only $23 \%$ of the subjects passed this suggestion. Item pass rates for all remaining suggestions in the self-scoring scale (and for all in the observers' scale) were between the lowest and highest rates reported by the 13 reference samples. Item pass rates, in general, were comparable to the original and the aggregated Hungarian sample, to a large-scale Australian sample, and to a current U.S. sample.

\section{Reliability}

Point-biserial item-scale correlations for the Hungarian and for the reference samples are displayed in Table 7. The measure of how the single suggestions are correlated to the total scale, with the given item removed, ranged from $r=.06$ (posthypnotic suggestion in observerscoring) to $r=.53$ (arm rigidity in self-scoring). Item-scale correlations measured by self-scoring and observer-scoring followed a similar pattern, as indicated by their Spearman rank-order correlation $\left(r_{\mathrm{S}}=.85\right.$, $p<.001$ ). Point-biserial correlation of eye closure (self-scoring) was almost as low as that in the German sample and lower than in any other sample; correlations for the other test suggestions, measured by both 


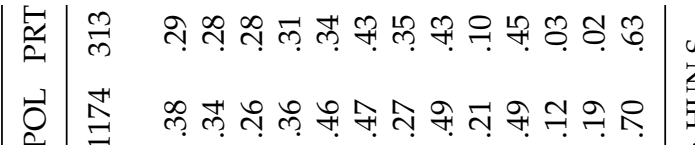

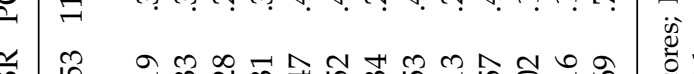

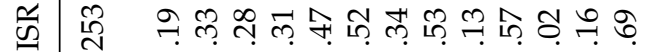

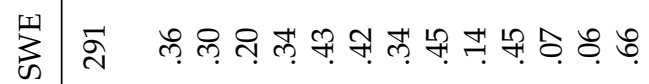

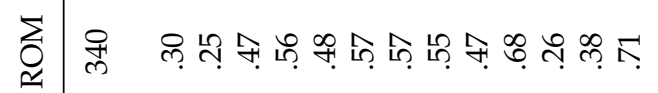

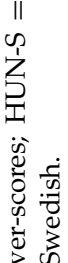
तो 
self-scoring and observer-scoring, were within the range of the values in the reference samples.

Reliability of the total scale-measured by the Kuder-Richardson (KR-20) coefficient-was .65 and .66 for the self-scores and the observer-scores, respectively. These values, although somewhat lower than those reported in the English versions of the HGSHS:A, are still within the range of the reference samples (from .62 in Germany to .71 in Finland for the non-English versions, and from .76 in Australia to .84 in Canada among the Anglophone countries).

To compare the Hungarian self-scores and observer-scores with the reference versions, point-biserial item-scale correlations were calculated by Spearman's method. Spearman rank-order correlation coefficients are presented in Table 8. Data suggested that the Hungarian version of the HGSHS:A - by both self-scoring and observer-scoring-is comparable to the reference samples, correlations ranking from $r_{\mathrm{S}}=$ .62 (Hungarian observer-scores and Italian self-scores) to $r_{\mathrm{S}}=.83$ (Hungarian and Spanish self-scores).

\section{DiscUsSION}

Normative data for the Hungarian version of the HGSHS:A are congruent with the previously published results from Europe, North America, and Australia. It is a novelty of the present approach to the HGSHS:A norms that, in addition to the traditional self-scoring (presented in all previous norms for HGSHS:A), trained observers also recorded and scored the behavior of the subjects. The two methods yielded a parallel pattern of results. Raw scores correlated at a level of $r=.82$, which is very similar to previous findings (e.g., Bentler \& Hilgard, 1963; Varga et al., 2012), and their means did not differ significantly from each other. Nevertheless, they were not identical; for example, the distribution of the two sets of scores was slightly divergent. Although the self- and observer score means are very similar, their composition shows a large discrepancy. As Varga et al. demonstrated, both measures are charged with systematic biases; for example, the observers may have various amounts of experience or may have unconscious expectancies about the subject's behavior, or the subjects may have altered perceptions of their own behavior, just to name a few. Take the example of the arm-lowering suggestion. The subject may estimate that his or her arm went down at least 15 centimeters (6 inches), so he or she would score one's performance in the response booklet accordingly ("passed item"). The trained observer, however, may see that the subject's hand actually moved down only 5 centimeters ( 2 inches), and, therefore, he or she scores it on his or her sheet as "failed item." Such differences may also have important implications in clinical hypnosis. As a 


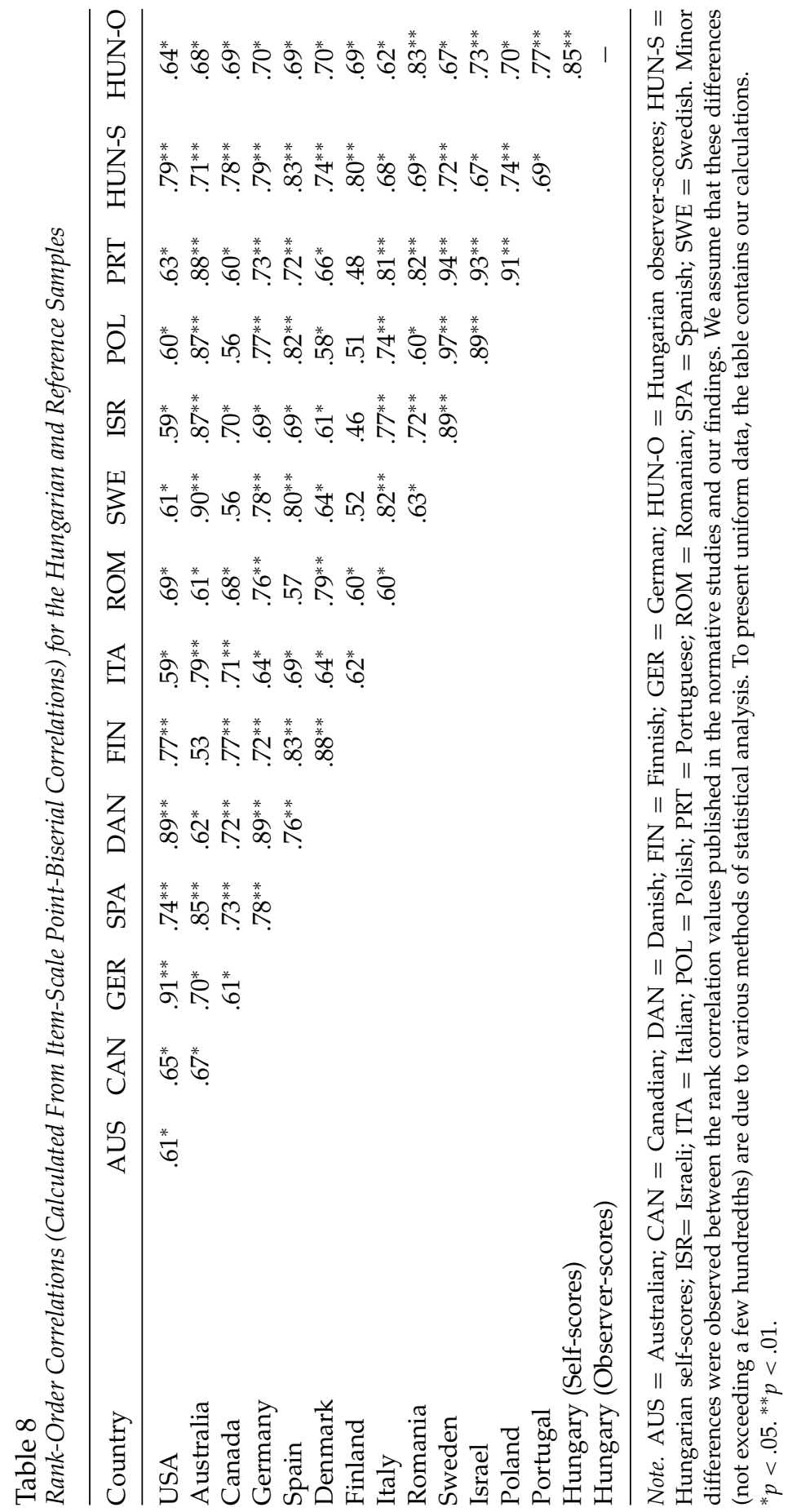


result of these discrepancies, the agreement between the subjects and their observers regarding passing an item is rather low, as measured with Cohen's kappa. Varga and her colleagues note that most hypnosis researchers take it for granted that the subjects' retrospective reports of hypnosis are valid and reliable measures of their hypnotizability, which is simply not true. It is just a subjective estimation of hypnotic capacity. Thus, they suggest not calling self-scoring an "objective" measure of hypnotizability, even if the authors of the scale did so. It seems quite reasonable to employ the behavioral observation of the hypnotized subjects and use these two measures-self-scores and observers' records-to corroborate each other.

One might argue that since, in other normative studies, the subjects were not observed (or at least it is not reported), the Hungarian method is not "standard." We are aware of the fact that this situation is somewhat different from that where no observation of the subjects takes place. Still, neither subjective nor observed hypnotizability scores in the Hungarian sample differed significantly from the scores of many other countries (Romania, Poland, Italy, Germany, Portugal, and Sweden), and even the existing differences in comparison with other countries (Spain, Canada, Australia, Israel, Finland, United States, Denmark) had quite small effect sizes. Indeed, in more recent large-sample studies of the HGSHS:A from the United States and Australia, hypnotizability scores were statistically similar to the Hungarian scores. We think it implies that it does not make a difference in the subjects' behavior if they are observed; therefore, the presence of observers in group hypnosis sessions does not seem to transgress standard conditions.

Hungarian hypnotizability scores proved to be lower than the Spanish, Finnish, original US, and Danish scores but higher than Canadian, original Australian, and Israeli data. Still, differences do not have a great effect size. When Hungarian scores were compared with a more recent Australian (McConkey et al., 1996) and US sample (Rudski et al., 2004), no significant differences were found. That gives further support to the notion that hypnotizability is a general trait that has the same level across different cultures. Certainly, that does not mean that we underrate or minimize the importance of genetic determination.

Cultural generality of hypnotic responsiveness is also underpinned by patterns in item pass rates and are quite similar in Hungary and in other countries. Still, it must be noted that, according to the observers, just $23 \%$ of the subjects passed Item 8 , communication inhibition. This proportion is remarkably less than how many subjects reported doing so in Hungary (44\%), or in any other country (from $42 \%$ in Australia to $74 \%$ in Spain). In our opinion, it is an interesting example of how the subjective feeling of one's own actions and the "tangible" and observable behavior may dissociate in hypnosis. Introspection may give an impression that you have made a very subtle and involuntary gesture, 
while a trained observer will not detect any movement. In other measures and comparisons to the reference samples, Hungarian subjects exhibited a similar pattern of hypnotic behavior to subjects from other countries.

Psychology students and psychologists exhibited a somewhat higher level of hypnotizability - as measured with observer-scoring - than nonpsychologists. Maybe the observers tended to be less "stringent" with psychology students and professionals, in terms of giving them higher scores than the nonpsychologists. It may also be that psychology professionals enter a hypnosis situation with greater motivation to "be hypnotizable." This possibility should be considered by experimenters when recruiting subjects: Nonpsychologist subjects may not have such a high motivation for experiencing hypnosis. Another possible explanation is that psychologists may tend to think in a more holistic manner, while IT/engineering professions may have a rather analytic way of thinking. The previous cognitive style is associated with higher while the latter with lower responsiveness to hypnosis (Morgan, 1972). A fourth possibility is that students and professionals may have more prior knowledge (and fewer misconceptions) about hypnosis than lay people, so it is easier for them to be absorbed in a hypnotic state. We have to note that the subsamples were quite small and heterogeneous. When an even more detailed categorization was used (not presented here because of its length), psychologists and artists proved to be the most hypnotizable, while professionals in law and IT/engineering scored the lowest on the HGSHS:A; the differences were, however, not significant. Residence of the subjects (capital region, county, town, or other settlement) does not seem to discriminate in level of hypnotizability.

Females turned to be significantly more hypnotizable than male subjects, although the magnitude of the effect is rather low. Our investigations on an HGSHS:A sample aggregated between 1975 and 2010 yielded a difference of greater effect size (around $d=0.3$ ); in individually administered SHSS:A and B scores (collected between 1973 and 2010), however, we have not found a significant gender difference (Költő et al., 2014). Given that the HGSHS:A and the SHSS:A, B are functionally equivalent-they just differ in the context of administration, group or individual-we argue that it is not the female and male subjects' hypnotic ability that is divergent but their hypnotic response, which may be attributed to social psychological mechanisms like sex role conformist behavior (e.g., Bem \& Lenney, 1976).

Because the literature on whether the size of the group influences hypnotizability is surprisingly sparse, we wondered if this aspect is relevant. Comparing the HGSHS:A scores of subjects tested in small ( $n=6$ to 10) groups were significantly lower than that of those who tested in larger ( $n=11$ to 49 ) groups. This classification is purely 
operational, formed by the actually available number of participants; further investigation with a greater variety in sample sizes and a larger number of groups is needed. If possible, it should be attempted to control the results for hypnotist variables. Nevertheless, our preliminary finding draws attention to the fact that we should not assume that group size does not count at all when administering HGSHS:A. Maybe in smaller groups, where it is easier for the subjects to monitor the others more closely, social comparison (Festinger, 1954) has a stronger impact, which may result in more inhibited behavior-and therefore lower hypnotizability - than in larger groups. This explanation, however, is speculative. Currently, we are analyzing our data to verify this notion.

In sum, our results indicate that the Hungarian version of the HGSHS:A is a viable method for testing subjects' hypnotic responsiveness under standard conditions in a group setting (at least for initial screening). We suggest that other researchers employ trained observers in the HGSHS:A sessions to complement the self-scoring of the subjects and thus arrive at a more accurate estimate of the hypnotizability of the subjects.

\section{ACKNOWLEDGMENTS}

The authors thank their students who participated as observers and assisted the research in multiple ways; and Cláudia Carvalho, PhD, and Anna Veres-Székely, PhD, for their help. We are also grateful for the anonymous reviewer for the valuable comments on the first version of the article.

\section{REFERENCES}

Araoz, D. L. (1979). Hypnosis in group therapy. International Journal of Clinical and Experimental Hypnosis, 27, 1-13.

Barnier, A. J., \& McConkey, K. M. (2004). Defining and identifying the highly hypnotizable person. In M. Heap, R. J. Brown, \& D. A. Oakley (Eds.), The highly hypnotizable person: Theoretical, experimental and clinical issues (pp. 30-60). London, United Kingdom: Routledge.

Bem, S. L., \& Lenney, E. (1976). Sex typing and the avoidance of cross-sex behavior. Journal of Personality and Social Psychology, 33(1), 48-54.

Benham, G., Smith, N., \& Nash, M. R. (2002). Hypnotic susceptibility scales: Are the mean scores increasing? International Journal of Clinical and Experimental Hypnosis, 50, 5-16.

Bentler, P. M., \& Hilgard, E. R. (1963). A comparison of group and individual induction of hypnosis with self-scoring and observer-scoring. International Journal of Clinical and Experimental Hypnosis, 11, 49-54.

Bentler, P. M., \& Roberts, M. R. (1963). Hypnotic susceptibility assessed in large groups. International Journal of Clinical and Experimental Hypnosis, 11, 93-97. 
Bergman, M., Trenter, E., \& Kallio, S. (2003). Swedish norms for the Harvard Group Scale of Hypnotic Susceptibility, Form A. International Journal of Clinical and Experimental Hypnosis, 51, 348-356.

Bongartz, W. (1985). German norms for the Harvard Group Scale of Hypnotic Susceptibility, Form A. International Journal of Clinical and Experimental Hypnosis, 33, 131-139.

Carvalho, C. (2013). Portuguese norms for the Harvard Group Scale of Hypnotic Susceptibility, Form A. International Journal of Clinical and Experimental Hypnosis, 61, 219-231.

Coe, W. C. (1976). Effects of hypnotist susceptibility and sex on the administration of Standard Hypnotic Susceptibility Scales. International Journal of Clinical and Experimental Hypnosis, 24, 281-286.

Cohen, J. (1988). Statistical power analysis for the behavioral sciences (2nd ed.). Hillsdale, NJ: Lawrence Erlbaum.

D’Eon, J. L., Mah, C. D., Pawlak, A. E., \& Spanos, N. P. (1979). Effects of hypnotists' and subjects' sex on hypnotic susceptibility. Perceptual and Motor Skills, 48, 1232-1234.

David, D., Montgomery, G., \& Holdevici, I. (2003). Romanian norms for the Harvard Group Scale of Hypnotic Susceptibility, Form A. International Journal of Clinical and Experimental Hypnosis, 51, 66-76.

De Pascalis, V., Russo, P., \& Marucci, F. S. (2000). Italian Norms for the Harvard Group Scale of Hypnotic Susceptibility, Form A. International Journal of Clinical and Experimental Hypnosis, 48, 44-55.

Festinger, L. (1954). A theory of social comparison processes. Human Relations, 7, 117-140.

Gősi-Greguss, A. C., Bányai, É. I., \& Varga, K. (1996, August). Hypnotists' hypnotic susceptibility. Paper presented at Eurohypnosis '96, 7th European Congress of Hypnosis, Budapest, Hungary.

Greguss, A. Cs. (1976). Hipnózis és személyiség [Hypnosis and personality] (Unpublished master's dissertation). Eötvös Loránd University, Budapest, Hungary.

Greguss, A. Cs., Bányai, É., Mészáros, I., Csókay, L., \& Gerber, A. (1975). A hipnózis iránti érzékenység standard vizsgálata magyar nyelven [Standard investigation of susceptibility to hypnosis in Hungarian (in Hungarian)]. Abstract. In L. Benedek \& T. Székely (szerk.), A Magyar Pszichológiai Társaság IV. Tudományos Jubileumi Nagygyúlése 1975 [IV. Scientific Convention of the Hungarian Psychological Association] (pp. 61-62). Budapest, Hungary: Magyar Pszichológiai Társaság.

Harvey, R. F., Gunary, R. M., Hinton, R. A., \& Barry, R. E. (1989). Individual and group hypnotherapy in treatment of refractory irritable bowel syndrome. The Lancet, 333, 424-425.

Hilgard, E. R. (1965). Hypnotic susceptibility. New York, NY: Harcourt, Brace \& World.

Holm, S. (1979). A simple sequentially rejective multiple test procedure. Scandinavian Journal of Statistics, 6, 65-70.

Kallio, S. P., \& Ihamuotila, M. J. (1999). Finish norms for the Harvard Group Scale of Hypnotic Susceptibility, Form A. International Journal of Clinical and Experimental Hypnosis, 47, 227-235.

Kirsch, I., Council, J. R., \& Wickless, C. (1990). Subjective scoring for the Harvard Group Scale of Hypnotic Susceptibility, Form A. International Journal of Clinical and Experimental Hypnosis, 38, 112-124.

Költő, A., Gősi-Greguss, A. C., Varga, K., \& Bányai, É. I. (2014). The influence of time and gender on Hungarian hypnotizability scores. International Journal of Clinical and Experimental Hypnosis, 62, 84-110.

Lamas, J. R., del Valle-Inclan, F., Blanco, M. J., \& Diaz, A. A. (1989). Spanish norms for the Harvard Group Scale of Hypnotic Susceptibility, Form A. International Journal of Clinical and Experimental Hypnosis, 37, 264-273. 
Laurence, J.-R., \& Perry, C. (1982). Montréal norms for the Harvard Group Scale of Hypnotic Susceptibility, Form A. International Journal of Clinical and Experimental Hypnosis, 30, 167-176.

Lichtenberg, I. (2008). Israeli norms for the Harvard Group Scale of Hypnotic Susceptibility, Form A. International Journal of Clinical and Experimental Hypnosis, 56, 384-393.

McConkey, K. M., Barnier, A. J., Maccallum, F. L., \& Bishop, K. (1996). A normative and structural analysis of the HGSHS:A with a large Australian sample. Australian Journal of Clinical and Experimental Hypnosis, 24, 1-11.

Morgan, A. H. (1972). Hypnotizability and "cognitive styles": A search for relationships. Journal of Personality, 40, 503-509.

Oakley, D. A. (2006). Hypnosis as a tool in research: Experimental psychopathology. Contemporary Hypnosis, 23, 3-14.

Reyher, J. (1962). A paradigm for determining the clinical relevance of hypnotically induced psychopathology. Psychological Bulletin, 59, 344-352.

Riegel, B. (2013). Hypnosis for smoking cessation: Group and individual treatment-A free choice study. International Journal of Clinical and Experimental Hypnosis, 61, 146-161.

Rudski, J. M., Marra, L. C., \& Graham, K. R. (2004). Sex differences on the HGSHS:A. International Journal of Clinical and Experimental Hypnosis, 52, 39-46.

Sadler, P., \& Woody, E. Z. (2004). Four decades of group hypnosis scales: What does item-response theory tell us about what we've been measuring? International Journal of Clinical and Experimental Hypnosis, 52, 132-158.

Sheehan, P. W., \& McConkey, K. M. (1979). Australian norms for the Harvard Group Scale of Hypnotic Susceptibility, Form A. International Journal of Clinical and Experimental Hypnosis, 27, 294-304.

Shor, R. E., \& Orne, E. C. (1962). Harvard Group Scale of Hypnotic Susceptibility, Form A. Palo Alto, CA: Consulting Psychologists.

Shor, R. E., \& Orne, E. C. (1963). Norms on the Harvard Group Scale of Hypnotic Susceptibility, Form A. International Journal of Clinical and Experimental Hypnosis, 11, $39-47$.

Siuta, J. (2010). Polish norms for the Harvard Group Scale of Hypnotic Susceptibility, Form A. International Journal of Clinical and Experimental Hypnosis, 58, 433-443.

Varga, K., Farkas, L., \& Mérő, L. (2012). On the objectivity of the scoring of Harvard Group Scale of Hypnotic Susceptibility. International Journal of Clinical and Experimental Hypnosis, 60, 458-479.

Weitzenhoffer, A. M., \& Hilgard, E. R. (1959). Stanford Hypnotic Susceptibility Scale, Forms $A$ and B. Palo Alto, CA: Consulting Psychologists.

Weitzenhoffer, A. M., \& Hilgard, E. R. (1962). Stanford Hypnotic Susceptibility Scale, Form C. Palo Alto, CA: Consulting Psychologists.

Zachariae, A., Sommerlund, B., \& Molay, F. (1996). Danish norms for the Harvard Group Scale of Hypnotic Susceptibility, Form A. International Journal of Clinical and Experimental Hypnosis, 44, 140-152.

\title{
Ungarische Normen für die Harvard Group Scale of Hypnotic Susceptibility, Form A
}

\author{
András Költő, Anna C. Gősi-Greguss, Katalin Varga und Éva I. Bányai
}

Abstrakt: Es wurden ungarische Normen für die Harvard Group Scale of Hypnotic Susceptibility, Form A (HGSHS:A) gezeigt. Die ungarische Übersetzung des HGSHS:A wurde unter standardisierten Bedingungen bei 434 Teilnehmern (190 Männer, 244 Frauen) unterschiedlicher Berufe 
angewandt. Zusätzlich zur traditionellen Selbsteinschätzung, wurde auch das hypnotische Verhalten durch professionelle Beobachter aufgezeichnet. Weibliche Teilnehmerinnen waren eher hypnotisierbar als männliche. Das gleiche zeigte sich bei Psychologiestudenten und Professionellen, die mit psychologischen Laien verglichen wurden. Die Hypnotisierbarkeit variierte zwischen verschiedenen Gruppengrößen. Die normativen Daten (wie Mittelwerte, Standardabweichungen und Reliabilitätsindikatoren) sind mit zuvor veröffentlichten Studien vergleichbar. Die Autoren kommen zu dem Schluß, daß die Messung von Beobachterergebnissen die Ökologische Validität der Skala erhöht. Die ungarische Version des HGSHS:A scheint eine verläßliche und valide Meßmethode der Hypnotisierbarkeit zu sein.

Stephanie Reigel, MD

Normes hongroises du l'échelle de susceptibilité hypnotique du Groupe de Harvard, formulaire A

András Költő, Anna C. Gôsi-Greguss, Katalin Varga et Éva I. Bányai

Résumé: Exposé des normes hongroises du l'échelle de susceptibilité hypnotique du Groupe de Harvard, formulaire A (HGSHS :A) La traduction hongroise du questionnaire HGSHS :A a été administrée dans des conditions normales à 434 participants (190 hommes, 244 femmes) de plusieurs professions. Outre l'auto-évaluation traditionnelle, le comportement hypnotique a également été consigné par des observateurs formés à cette fin. Les femmes se sont avérées plus hypnotisables que les hommes, de même que les étudiants en psychologie et les professionnels de cette discipline, comparativement aux autres professions. Le degré d'hypnotisabilité variait au sein de groupes de tailles différentes. Les données normatives - y compris la moyenne, l'écart-type et les indicateurs de fiabilité - sont comparables à d'autres résultats publiés antérieurement. Les auteurs en concluent que l'ajout des résultats des observateurs augmente la validité écologique du l'échelle. La version hongroise du HGSHA :A semble être une mesure valable et fiable d'hypnotisabilité.

JOHANNE REYNAULT

C. $\operatorname{Tr} .(S T I B C)$

Normas Húngaras de la Escala Grupal Harvard de Susceptibilidad Hipnótica, Forma A

András Költő, Anna C. Gősi-Greguss, Katalin Varga, y Éva I. Bányai

Resumen: Se presentan los datos normativos Húngaros de la Escala Grupal Harvard de Susceptibilidad Hipnótica, Forma A (HGSHS:A). La traducción Húngara de la HGSHS:A se administró bajo condiciones estándares a 434 participantes (190 hombres, 244 mujeres) en distintas profesiones. Adicionalmente a la autoevaluación tradicional, observadores entrenados registraron la conducta hipnótica. Las mujeres participantes mostraron ser más hipnotizables que los hombres; como también lo fueron los estudiantes 
y profesionistas psicólogos comparados a los no psicólogos. La hipnotizabilidad varió entre grupos de distintos tamaños. Los datos normativos -incluyendo medias, desviaciones estándar, e indicadores de fiabilidad- son comparables con resultados publicados previamente. Los autores concluyen que el medir las puntuaciones de observadores incrementa la validez ecológica de la escala. La versión Húngara de la HGSHS:A parece ser una medida de hipnotizabilidad fiable y válida.

Omar SÁnchez-Armáss Cappello, PhD Autonomous University of San Luis Potosi, Mexico 